\title{
Contributions of the SocialNEET project to the development of skills for active life
}

\author{
Juliana Costa $^{1}$, Arlinda Semedo ${ }^{2}$, Sofia Bergano ${ }^{3}$, Vitor Gonçalves ${ }^{4}$ \\ ${ }^{1}$ Instituto Politécnico de Bragança, Portugal, ${ }^{2}$ Instituto Politécnico de Bragança, Portugal, \\ ${ }^{3}$ Centro de Investigação em Educação de Adultos e Intervenção Comunitária (CEAD), \\ Instituto Politécnico de Bragança, Portugal, ${ }^{4}$ Research Centre in Basic Education (CIEB), \\ Instituto Politécnico de Bragança, Portugal.
}

\begin{abstract}
The SocialNEET project, promoted at the Polytechnic Institute of Bragança, between November 2020 and February 2021, whose main goal is the (re)integration in the labour market of young people, through the creation of innovative social business solutions and finding employment in companies or associations in the social sector. It provides learning for active life and education for entrepreneurship, through the participation of facilitators (students of higher education) who will simplify the connection between mentors (successful entrepreneurs and consultants) and young NEET (not in education, employment or training), in the sense of creating life projects, social projects or innovative social business and job search solutions in companies or associations in the social sector. The essential focus of this article corresponds on the training of facilitators $(N=10)$ and its objective is to understand the capacities developed by them in this process, as well as the limitations felt and the strategies to minimize them. For this purpose, a qualitative case study was carried out based on the documentary analysis of the training, namely an observation grid, a questionnaire to the trainees and the reflective analysis of the trainers. We conclude that the strengthening of soft skills, intercultural communication and education for entrepreneurship may be the priority ways to promote social improvements and thus contribute to the 2030 Agenda.
\end{abstract}

Keywords: Soft skills; intercultural communication; social entrepreneurship; youth employability. 


\section{Introduction}

The creation of opportunities for youth employment, namely for NEET (not in education, employment, or training) in the age group between 18 and 29 years old, is among the main public policies promoted by the European Union (EU) as a way of promoting more equal territories. In this sense, through the EEA and Norways Grants Funds for Youth Employment, it finances the SocialNEET Project in seven European countries (Slovenia, Spain, Greece, Italy, Latvia, Poland, and Portugal), with the main objective of generating opportunities for young people to enter the labor market or create knowledge to promote self-employment, fighting social inequality, meeting the 2030 Agenda (SocialNEET, n.d.). The SocialNEET Project provides spaces for the provision of training workshops on entrepreneurship education, to contribute to the development and recognition of soft and hard skills in NEET young people, skills increasingly required in job search. The SocialNEET Project, in Portugal, had its NEET meeting point, promoted by the Polytechnic Institute of Bragança (IPB), acting in the training of higher education students to assist the NEET youth training process, contributing to the training process of professionals better prepared for the need of the job market and for breaking the paradigm of the search for the first job.

This work consists of a mixed case study, aimed at understanding the perceptions developed by higher education students, called facilitators $(\mathrm{N}=10)$, in the support of the training process for young NEET. In addition to an observation grid used by trainers to record actions, interactions or iterations and results from relevant moments, the main instrument for data collection used was an online questionnaire or survey, in Google Forms format, applied to facilitators at the end of the process NEET training. This paper presents a brief introduction about the SocialNEET Project, following the state-of-the-art of SocialNEET, the methodology of the work, the perceptions and reflections of the activities developed by the facilitators and the final considerations of the study.

\section{SocialNEET: State of the Art}

Education should be the main factor to reduce social disparities among young people and, although in the last decades their number has increased in the school context, this has not translated into positive numbers in employability, since in the year 2020, more of 5.5 million young people were in NEET status in the EU (Lorinc, Ryan, D'Angelo, \& Kaye, 2019).

In this sense, the challenge of promoting more equal territories on the European continent is to offer training opportunities that contribute to the promotion of NEET employment, as this is a public with great difficulty in accessing the labor markets (Lorinc et al., 2019). In addition, 2030 Agenda, -which is a plan of action for people, planet and prosperity, composed by 17 Sustainable Development Goals (SDG) and 169 targets, in the SDG 4, "Quality Education", advocates increasing the educational offer for young people who 
contribute to improving literacy skills, "technical and professional skills, which lead to employment, work decent and entrepreneurship" (United Nations, n.d.). It should also be noted that, with the globalized economy, stimulating entrepreneurship means providing young people with skills to create their own jobs and, thus, lead them to social improvement (Gonçalves, 2020).

In this context, since 2017, the EEA Grants Funds has a plan of action to address more than 25000 young people by the actions in education or training, support to active job search, create jobs in NGOs and start up a business. The actions are held by the Fund for Youth Employment, in 25 projects like the Active Citizen Fund and SocialNEET (EEA Grants, n.d.). SocialNEET is part of a European social policy recommendation for the creation of an ecosystem aimed at combating youth unemployment, by promoting opportunities for NEET employability in the third sector, namely in social organizations, and in traditional employment models, as well as in entrepreneurship education, to create business models that lead to social improvement (SocialNEET, n.d.).

\subsection{Young NEET}

The acronym NEET is used in the EU to define groups of young people between 15 and 34 years old who are not working in society, being considered a serious economic and social problem for the 27 Member States (Giret, Guégnard, \& Joseph, 2020; Jongbloed \& Giret, 2021). SocialNEET training seeks, through the provision of education for entrepreneurship, to contribute to the reduction of social disparities through the creation of self-employment, promoting the breaking of the first job paradigm and, therefore, fighting stereotypes linked to NEET terminology. According to Jongbloed and Giret (2021), the NEET terminology contributes to increasing the exclusion of young people from relationships in society, promoting the creation of stereotypes that cause their greater vulnerability in the labor market, since they are conceptualized as young people with few developed skills and low capacity for problem solving, with little appreciation of the professional curriculum, leading to social aggravations such as scarce employment opportunities, low pay and poverty. Still, according to Jongbloed and Giret (2021) and Lorinc et al. (2019), the NEET condition acts in the ability to recognize the soft skills and well-being of young people, which can lead to depression, low self-esteem, causing problems in relationships with family and friends, in addition to other social problems. In this sense, it is important to have an educational / training intervention aimed at self-valorization, the (re)construction of a positive and realistic image of oneself, which allows the identification of your abilities and potentialities, as well as the areas of competence that need to be worked and developed. 


\subsection{Facilitators of the youth NEET}

The creation of opportunities that contribute to the understanding of public social policies is an urgency in European territory and should be part of the training offer of higher education institutions, since the access of young people to education promotes improvements in social conditions and leads the construction of more inclusive spaces and a more equal society (Gonçalves, 2020; Lorinc et al., 2019). Therefore, training professionals who are more attentive to social needs, with the ability to intervene and propose innovative solutions must be among the training competencies offered to students in the various areas of higher education, and so it is understood that promoting spaces for entrepreneurship, associated with the concept of soft skills and intercultural communication, enables the construction of critical thinking, the development of knowledge and a greater capacity for intervention by future professionals (Blázquez, Zaldívar, \& Leite, 2018; Gonçalves, 2020; Pinto \& Reshma, 2021). For Gonçalves (2020), the knowledge provided by entrepreneurship contributes to the development of soft skills such as resilience, leadership skills and teamwork, fundamental requirements for the job market.

In this sense, the education for entrepreneurship offered by SocialNEET training contributes to the training process of future professionals more aware of their role as a global citizen, acting in the construction of business opportunities that lead to social justice and a better generation of income, going to meeting of sustainable development. We can affirm that training facilitators, to act as peers in the training of young NEET, contributes to the development of individual and corporate responsibility of those responsible, in order to agents of social change in the context of professional performance.

\subsection{Entrepreneurship education of the NEET Facilitators}

Entrepreneurship, in all its typologies, has been a way to reduce inequalities, either through the creation of innovative business models or through the promotion of projects of that lead to personal development that is reflected in improvements for society (Gonçalves, 2020). The 2030 Agenda clearly shows entrepreneurship education in the SDGs as a goal to be achieved in favor of sustainable development (United Nations, n.d.). It is necessary to educate the individual for social and business skills, to awaken creativity and innovation, and to train professionals with the ability to recognize soft skills and intercultural communication as elements of strategic thinking to achieve social equity (Blazquez et al., 2018; Gonçalves, 2020). In the perspective of Vieira and Marques (2014), soft skills are a set of personal and interpersonal skills that provide ascendants or competitive advantages for employment, for sustaining employability, and for promoting entrepreneurship. 


\section{Methodological framework}

\subsection{Contextualization of the project}

In Portugal, more specifically in Bragança city, the NEET meeting point, destined for clarifying and making available the SocialNEET training offer, was promoted by the Polytechnic Institute of Bragança (IPB). The first training session took place at the School of Education (ESE/IPB), between November 2020 and February 2021, in a blended learning approach. The sample was constituted on a voluntary basis, through registration on forms made available on the school's web portal, being formed by higher education students in different training areas $(\mathrm{N}=10)$. The training for NEET facilitators consisted of the following modules:: i) intercultural communication through the course "The peculiarities of intercultural communication"; ii) recognition of soft skills and self and straight knowledge ; and iii) education for entrepreneurship, using idea generation processes in the context of Design Thinking and the Walt Disney Creative Process, using brainstorming, SCAMPER (S: substitute, C: combine, A: adapt, M: modify, P: put another use, E: eliminate and R: reverse), empathy map and the business model canvas proposed by Alexander Osterwalder (Gonçalves, 2020). The training also had a practical part, where the facilitators, through the learning by doing methodology, were able to make use of the acquired knowledge, acting in the intermediation between trainers and NEET young people, in the training processes, asking the mentors and trainers when they need.

\subsection{Methodology and procedures for collecting and processing information}

The research was based on a mixed case study (quantitative and qualitative) to analyze the gains promoted by SocialNEET training. The data collection was carried out through an online questionnaire or survey, in the Google Forms format, divided into two parts. One of which was aimed to the sociodemographic understanding of the respondents, with data collection on: the type of facilitators (Challenge-Based Innovation or voluntary), sex, age, level of education and experience in the labor market. The second part was composed of thirty-six items divided into three blocks of twelve items each for understanding the perception of the competencies of: i) intercultural communication; ii) recognition of soft skills; and iii) education for entrepreneurship, being evaluated on a five-point multi-item opinion scale (Likert scale), where one represented "did not contribute anything" and five "contributed a lot". The survey was made available to the facilitators at the end of the SocialNEET training and the treatment of the data proceeded using a specific statistical program the IBM SPSS Software (Statistical Package for the Social Sciences). In addition to this data collection instrument, an observation grid was also used where each of the trainers recorded the most relevant actions, interactions, and iterations that he considered important, not forgetting the identification of individual or group results. 


\subsection{Characterization of participants}

The participants in this study correspond to two different typologies: volunteer facilitators and CBI facilitators (participants enrolled in the " $10 \%$ up to you" program of the IPB platform for entrepreneurship, employability, and training innovation (https:/if.ipb.pt), namely in the Challenge-Based Innovation (CBI) module). This module corresponds to real challenges launched by structures of the IPB or external partners (in this case the SocialNEET project team), who throughout a semester, carrying out teamwork, demonstrated and developed technical and transversal knowledge and skills necessary for the execution of a work plan. The volunteer facilitators corresponded to other types of facilitators who were not obliged to complete any specific program other than that required in the SocialNEET project. The number of respondents was 10 facilitators, $80 \%$ of whom are CBI facilitators $(\mathrm{N}=8)$, and $20 \%$ of whom are voluntary facilitators $(\mathrm{N}=2)$, of whom $80 \%$ are female $(\mathrm{N}=8$; $\mathrm{CBI}$ and volunteers) and $20 \%$ male $(\mathrm{N}=2 ; \mathrm{CBI})$. The age of the facilitators is between 20 and 43 years $(\mathrm{N}=10)$, with an average of 27 years for individuals, and a standard deviation of 1,059 years. Regarding the level of study, $80 \%$ are studying at undergraduate level $(\mathrm{N}=8)$, and $20 \%$ at master's level $(\mathrm{N}=2)$.In a total of 10 respondents, $90 \%$ of the facilitators $(\mathrm{N}=9)$ claimed to have some paid work experience, and only $10 \%(\mathrm{~N}=1)$ said they had no work experience. This demonstrates that the facilitators, although still in the process of higher education, in parallel with their studies, experienced the opportunities and challenges for entering in the labour market.

\section{Reflections on the activities carried out}

The activities developed in SocialNEET training sought to contribute to the development of skills in facilitators, in order to prepare more active professionals for the creation of opportunities to enter the job market. Among the skills worked on, intercultural communication, provided facilitators with a reflection on the importance of culture and the ability to communicate in business relationships, being worked through the course "The peculiarities of intercultural communication", taught by Professor Skaiste Kalininaite from the Department of Communication at the Kaunas University of Applied Sciences, Lithuania. In this context, the facilitators' perception of the skills acquired in the training process obtained a global average of 52.0 points and a standard deviation of $6.815 \%$, with the lowest averages for the statements: i) reflect on the creation of stereotypes and their negative effects on society; ii) knowing how to communicate with others; and iii) communicate openly, clearly, and frankly (4.00). The highest averages (4.6) were found in the statements: i) expand my knowledge about intercultural differences between peoples; ii) understand the importance of respect in sharing spaces between different nationalities; and iii) realize the importance of understanding culture within business relationships. The overall value found in the analysis of the responses was greater than 3, allowing to infer that the course for intercultural 
communication contributed to the development of intercultural communication skills in NEET facilitators.

Following the SocialNEET training, the soft skills recognition competence addressed through group dynamics on the theme of self and hetero knowledge, the facilitators worked on the ability to understand that personal and professional skills are transferable between knowledge fields, the same being considered important elements for teamwork. The results found for this competence obtained an average of 52.6 points and a standard deviation of $7.862 \%$, the statement with the lowest average: reflecting on me and getting to know me better (4.20) and those with the highest averages: i) to help me know my neighbor (others); and ii) working in a diversified team (4.70). Through the analysis of the data, it can be inferred that the SocialNEET training contributed to the construction of the individual's critical sense and the self-recognition of soft skills as an asset for the valorization of the curricula of future professionals. For the field of entrepreneurship, the use of the learning by doing methodology allowed the facilitators a practical experience for which they were trained. In this sense, the global average obtained was 51.1 points and a standard deviation of $8.504 \%$, with the lowest average for the statement: learning to draw a map of empathy for customers (3.9), and the highest averages for: i) develop skills that enabled me to act as a facilitator $(4,6)$; and ii) know and use free tools useful for the process of building a project $(4,5)$. Therefore, it can be inferred that, sometimes, entrepreneurship education makes use of tools that some students have difficulties in understanding, requiring more time for learning. That said, it can be inferred that SocialNEET training contributed to the development of entrepreneurial skills of the facilitators through the contents worked on, namely within the scope of Walt Disney Process, which contributed to the development of understanding of business models and the acquisition or improvement of innovation and creativity skills in the facilitators' profile.

The training process where also an important part of the gains for the facilitators, and it was clearly evident in the evaluation of CBI facilitators that in the end of the project had to demonstrate communication skills, presenting clearly, reasoned and sustainable ideas and solutions developed, achieving all facilitator a positive marks.

In a global way, it can be said that the SocialNEET project contributed positively to the development of the entrepreneurial spirit, intercultural communication, and soft skills competences in higher education students, thus making them professionals better prepared to face the training challenges and future challenges in the labor market.

\section{Conclusions}

The SocialNEET Project, through a profile that recognizes the importance of the education for entrepreneurship and of the soft skills and intercultural communication, promoted reflection for the development or improvement of personal and professional skills, in higher 
education students, to contribute to a more critical and participatory performance of these future professionals not only in this training for NEET, but also in society in general. Through peer facilitation (NEET and facilitators), it provided the group of facilitators with an opportunity for tutoring and practical skills within intercultural communication, the recognition of soft skills and entrepreneurship education.

Through the training actions of the project, the facilitators were able to understand that entrepreneurship means much more than a business model, being above all a way to build knowledge, and allow the construction of a more equal society.

\section{Acknowledgment}

This work has been supported by FCT - Fundação para a Ciência e Tecnologia within the Project Scope: UIDB/05777/2020.

\section{References}

Blázquez, A. L. T., Zaldívar, C. R. V., \& Leite, E. F. (2018). Emprendimiento ¿Actitud o como competencia del capital humano? Una mirada conceptual desde la Universidad de Holguín, Cuba. HOLOS, Ano 34, 8, 109-137. DOI: 10.15628/holos.2018.7954

EEA Grants (s. d.). Fund for Youth Employment. Iceland, Liechtenstein, Norways Grants and Norways Grants [Web page]. Acedido em 17 de outubro de 2020 em https://eeagrants.org/topics-programmes/fund-youth-employment

Giret, J-F., Guégnard, C., \& Joseph, O. (2020). School-to-work transition in France: the role of education in escaping long-term NEET trajectories. International Journal of Lifelong Education. DOI: 10.1080/02601370.2020.1796835

Gonçalves, V. (2020). Educação para o empreendedorismo e tecnologias associadas. Pedagogias digitais no ensino superior. Coleção Estratégias de Ensino e Sucesso Académico: Boas Práticas no Ensino Superior. Cap. 9, 8,169-215.

Jongbloed, J., \& Giret, J-F. (2021). Quality of life of NEET youth in comparative perspective: subjective well-being during the transition to adulthood, Journal of Youth Studies.

Lörinc, M., Ryan, L., D’Angelo, A., \& Kaye, N. (2019). De-individualising the 'NEET problem': An ecological systems analysis. European Educational Research Journal. https://doi.org/10.1177/1474904119880402

Nações Unidas (s. d.). 4 Educação de Qualidade. Centro Regional de Informação para a Europa Ocidental [Web page]. Retrieved from https://unric.org/pt/objetivo-4-educacaode-qualidade-2/

Pinto, A. P., \& Reshma KJ (2021). Impact of Project-Based Learning on Entrepreneurial and Social Skills Development. Journal of Engineering Education Transformations. 34, 593 598. ISSN 2394-1707.

SocialNEET (s. d.). What is SocialNEET [Web page]. Acedido em 17 de novembro de 2020 em http://socialneet.eu/what-is-socialneet/ 
Vieira, D. A., \& Marques, A. P. (2014). Preparados para trabalhar? Um estudo com diplomados do ensino superior e empregadores. [s.l.]: Forum estudante. 